\title{
Design Opportunities for AAC and Children with Severe Speech and Physical Impairments
}

\author{
Seray Ibrahim \\ UCL Knowledge Lab \\ University College London, \\ London, UK \\ s.ibrahim@ucl.ac.uk
}

\author{
Asimina Vasalou \\ UCL Knowledge Lab \\ University College London, \\ London, UK \\ a.vasalou@ucl.ac.uk
}

\author{
Michael Clarke \\ Div of Psychology \& Lang Sciences \\ University College London, \\ London, UK \\ m.clarke@ucl.ac.uk
}

\begin{abstract}
Augmentative and alternative communication (AAC) technologies can support children with severe speech and physical impairments (SSPI) to express themselves. Yet, these seemingly 'enabling' technologies are often abandoned by this target group, suggesting a need to understand how they are used in communication. Little research has considered the interaction between people, interaction design and the material dimension of AAC. To address this, we report on a qualitative video study that examines the situated communication of five children using $\mathrm{AAC}$ in a special school. Our findings offer a new perspective on reconceptualising AAC design and use revealing four areas for future design: (1) incorporating an embodied view of communication, (2) designing to emphasise children's competence and agency, (3) regulating the presence, prominence and value of AAC, and (4) supporting a wider range of communicative functions that help address children's needs.
\end{abstract}

\section{Author Keywords}

AAC, children, multimodal communication, accessibility, design.

\section{ACM Classification Keywords}

H.5.m. Information interfaces and presentation (e.g. HCI): Miscellaneous; K.4.2. Computer and society: Social issues: Assistive technologies for persons with disabilities.

\section{INTRODUCTION}

Young children who have limited or no functional speech are at risk in all aspects of their development, affecting their social interaction and overall quality of life [26]. It is common for children with severe speech and physical impairments (SSPIs), to adopt a more passive role during interactions [25] and have severe and impoverished independent access to a range of play and language resources in early life. High-tech augmentative and

Permission to make digital or hard copies of all or part of this work for personal or classroom use is granted without fee provided that copies are not made or distributed for profit or commercial advantage and that copies bear this notice and the full citation on the first page. Copyrights for components of this work owned by others than ACM must be honored. Abstracting with credit is permitted. To copy otherwise, or republish, to post on servers or to redistribute to lists, requires prior specific permission and/or a fee. Request permissions from Permissions@acm.org.

CHI 2018, April 21-26, 2018, Montreal, QC, Canada (C) 2018 Association for Computing Machinery. ACM ISBN 978-1-4503-5620-6/18/04_..\$15.00 https://doi.org/10.1145/3173574.3173801 alternative communication (AAC) devices offer opportunities for children to produce electronic speech derived through lexical or symbolic representations of language but these can be difficult to learn to use, particularly for children who have emerging literacy skills or those who find it more difficult to access learning opportunities [23]. Associated with these learning demands, the high abandonment rate of AAC [1,18,31] suggests that these devices are not fully usable for children for supporting communication in everyday, routine activities.

The research field of AAC has evolved over the past two decades bringing together practitioners, researchers and industry stakeholders with the common goal to develop new theoretical and empirical understandings surrounding communication involving people who have little or no functional speech. However, to date this research has not 'talked back' to interaction designers tasked with designing $\mathrm{AAC}$ and new technologies for children with SSPI. At the same time, child computer interaction researchers have focused on methodological questions regarding the involvement of children with SSPI in the design process, for example, challenges involving them in legitimate ways so that their contributions can inform design decisions [2,6], rather than contributing a critical view on technology design. There is thus a need to further understand the relationship between child communication and AAC design toward maximising the opportunities for supporting communication for young children with SSPIs [27].

This paper seeks to address this area through an empirical qualitative, 14-week field study that examined how young children with SSPI's communicated with their peers and adults when AAC technologies were present. Following $\mathrm{AAC}$ research that recognises situated communication, yet taking a design orientation, our research seeks to understand how communication manifests within typical everyday interactions involving children and their AAC. Our goal is to define the range of design opportunities and challenges that characterise these interactions. This paper makes three contributions. First, it adds to the empirical research concerned with how communication manifests for children with SSPIs, by emphasising how communication is shaped by design and people. Second, it demonstrates a systematic and reflexive methodological approach for investigating communication in children who use a range of modes to communicate. Third, it reveals four new areas for 
future design of technology and AAC: incorporating an embodied view of communication; designing to emphasise children's competence and agency, regulating the presence, prominence and value of AAC, and; supporting children in maintaining self-initiated communication.

\section{RELATED WORK}

Augmentative and Alternative Communication (AAC)

AAC strategies and techniques are often used in a range of contexts by people who have little or no functional speech. The modern era of AAC began in the 1950s with the development of a collection of unaided and aided techniques. These included strategies for gesture and signing, and paper-based communication aids.

Electronic communication devices began to emerge in the 1960s [41] and since then, the research-led field of AAC has worked at advancing ways of understanding and supporting communication that is aided through technology. Fig. 1 presents an example of an electronic device and language display. Typically, users access these devices directly through finger/fist or eye control or indirectly by scanning and selecting cells. In the wake of a burst of new technologies for speech generation, there have however been careful reminders that it is communication, not technology, that should remain the central focus [24]. In warning of the dangers of taking a technology-centric approach to communication, Light and McNaughton allude to the risks of communication interventions beginning and ending solely with the provision of an AAC device [28]. Highlighting the broader complexities that surround communication involving AAC devices, Kraat emphasised the distributed nature of communication 30 years ago, describing interactions that are made up of the participants, the communication setting and the codes and rules for language use amongst other factors [20]. For Moser, it is these factors - social, technological, human - and their ordering in specific ways that creates disability [30].

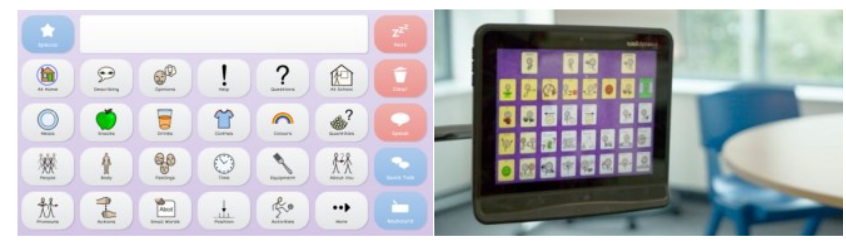

Figure 1. Example electronic AAC device showing language display by $($ Smartbox Assistive Technology Ltd 2017 (left) and mounted eye gaze device by () Tobii Dynavox 2017 (right)

AAC research has sought to take this situated view advocated by Light and Kraat by recognising that communication is co-constructed, influencing and being influenced by the context in which it manifests. Thus, studies on interpersonal communication involving people who have complex communication difficulties and AAC devices reject the notion of a sender-receiver model which solely credits the transmitted message, instead identifying the role of wider resources that people use for communication. Accordingly, this empirical work has sought to understand the practical ways that meaning is accomplished in naturally occurring interactions [5,14].

One strand of research has focused on the sequences in turn taking during conversations between people who use AAC and naturally speaking partners. Bloch \& Wilkinson [6], for example, studied repairs related to problems with achieving shared understanding in conversations involving adults with acquired aphasias and their conversation partners. Repair in its broadest sense concerns how participants organise interaction when some form of mistake has been made and is corrected, but it also incorporates a wider range of issues beyond the realisation of errors [36]. In analysing the sequences of participant turns and actions, Bloch \& Wilkinson found that whilst the use of AAC devices at key moments made previously unintelligible speech now intelligible, i.e. through speaking a letter or word more clearly, it did not always make it understandable for the communication partner as $\mathrm{s} / \mathrm{he}$ was unable to always understand the relationship between the AAC turn and prior talk. This suggests that the accomplishment of understandability may be contingent on prior turns, which creates coherence of context, and needs to be maintained in AAC mediated talk.

Clarke and Wilkinson [9] examined how turn taking involving $\mathrm{AAC}$ is organised focusing on children's peer interactions. The authors found that naturally speaking children typically organised the structure of interaction sequences, initiated interaction sequences more frequently and produced more contributions. For example, naturally speaking children would organise points in the conversation in which minimal AAC mediated contributions (e.g. single words) could be understood. In connected work, when the conversation exchanges were initiated by children using AAC devices, these could be difficult for the naturally speaking peer to understand when it was unclear how they were connected to the previous sequence [10], thus extending Bloch and Wilkinson's findings by showing when and why repairs occur [6].

Other research by Higginbotham [14] explored the communicative multimodal resources of people with complex communication needs to show how they perform utterances using a variety of signs and structures. In observing that people engage in activities with a main goal of achieving common ground, this research shows that people attend to a range of temporal-contextual requirements in the moment through actions that extend beyond the AAC device or even language alone. For example, one of the study participants with complex communication difficulties started by using their electronic AAC device but then quickly opted to use a simple alphabet board, in response to their communication partner's physical orientation which apparently made this mode of communication more effective. Besides evidencing the dynamic adjustment of communication modes employed by $\mathrm{AAC}$ users, this example suggests that $\mathrm{AAC}$ devices are 
sometimes perceived as inhibiting communication interactions or delaying communication further, leading to the selection of a more appropriate mode.

\section{AAC and $\mathrm{HCl}$}

In contrast to the theoretical and empirical focus of AAC research on existing technology use, $\mathrm{HCI}$ has contributed to the field of AAC through interaction design. Black and colleagues [4] chose to focus on improving access to nonverbal children's personal narrative construction based on research showing that narratives are an important part of language development and a commonly used strategy for advancing social communication. Taking a user centred design approach, they worked with school aged children who had little or no functional speech and diverse profiles in terms of their age and mobility. Together, they designed an accessible mobile application that created context for personal narrative construction, e.g. by tracking interactions with people, objects and locations, which the children effectively accessed and used with a voice output multiple message switch. Another study by Hornoff et al [16] drew on previous evidence showing that women with Rett syndrome greatly enjoy listening to music and postulated that technologies can offer autonomy in independently accessing music. They designed and evaluated an accessible interactive media system with five women with Rett syndrome and their families. The authors identified that their technology would likely be useful in a context whereby there is an existing lack of appropriate assistive technology for this population. de Faria Borges et al [11] took a therapeutic and learning perspective on AAC using mixed methods to design a customised communication device for a child with cerebral palsy. They worked with the school and therapy team to create a system that would support the child's language development based on the words and symbols that they were learning in school.

This previous work has tended to start with a given orientation or 'frame' on technology, focusing on new technology development. The plurality of perspectives represented in these design projects have rarely aligned with the challenges, or interacted with the theoretical lenses taken in AAC research as covered in the previous section. For example, the reductive sender-receiver model for communication, which assumes communication is centred on the transmission of information from one participant to another, has been critiqued by AAC scholars in favour of a situated model of communication. Despite this, several design researchers [4,8,38] including de Faria Borges [11] have applied the sender-reciever model by focusing solely on the role of AAC users and their capability to use the features of a technology as they transmit a message.

The importance of bridging theoretical AAC research with inventive interaction design that has relevance to the concerns of AAC users is best encapsulated in Pullin's design research. Aimed at reframing the 'design problem' driving existing assistive technology more broadly, Pullin
[33] proposes an interdisciplinary turn to AAC design. By drawing from creative disciplines such as fashion, Pullin introduces a new set of values that recast how existing assistive technology is designed. Moreover, in work that focuses on a known problem for AAC technologies, i.e. synthetic speech quality and tone, Pullin and Hennig [34] employ critical design to expose design challenges as provocations for future design work. They present the six speaking chairs project inviting people to engage in a dialogue that disrupts the traditional ways that synthesized speech for AAC has typically been construed. This design research intends to move the designer away from focusing on functional communication to wider socio-cultural concerns such as personal taste, identity and cultural norms, to name a few.

Similar to Pullin's work, the present research seeks to identify new design opportunities for AAC technology by taking a critical view on how this technology currently mediates communication. Our research focuses on the use of AAC by children to communicate with adults and their peers. Despite the thrust to involve children in design more broadly, children are still a largely under-represented group in AAC design. Moreover, even though a vast volume of AAC technologies is aimed at children, these are largely under-utilised and often abandoned [1,18,31]. Our approach is to bring AAC theories into the space of technology design. In doing so, we address the following questions:

1. What kind of communication is achieved in interactions involving children and AAC technologies? (RQ.1)

2. How do AAC technologies and their design shape communication? (RQ.2)

3. How does technology fit with other resources that children have when advancing their communication? (RQ.3)

\section{METHODOLOGY}

\section{Context}

To reach the population of interest, the study took place in a primary special educational needs school in a major city in the UK where children deemed to have receptive language skills outweighing their expressive language abilities are often assessed for and provided with AAC devices. This is the primary context where children learn how to use AAC and are supported to become competent communicators.

Having previously worked in the school as a speech and language therapist with a clinical specialism in AAC, the first author was previously involved in planning and delivering the communication curriculum jointly with the teaching team as well holding a detailed understanding of the children's day to day experiences of school life, their interests and some knowledge of their home lives. This prior contact was beneficial in the context of this research for minimising obstacles, anxieties and nervousness in not knowing how to interact with children who have complex 
communication needs [15]. Given the role of the first author as a participant-researcher, it was important to maintain neutrality during both data collection and analysis [32]. To manage this, the authors met regularly to reflexively discuss and evaluate the researcher's actions; for example, managing expectations of being a familiar adult to people in the school to addressing power shifts from an authoritative adult within the setting to being a researcher.

The research took place over the course of 14 weeks between November 2016 and February 2017 and consisted of 23 visits in total. Ethical approval was initially obtained through the university ethics board. Additionally, on-going discussions were held with co-authors, school staff and research participants to reflect on emergent ethical risks throughout the course of the research. For example, given children's learning difficulties it was deemed important to renew consent on each visit so that they understood what their participation involved and how their contributions would be used. One of the ways that we approached consent was by explaining information sharing. We used a post box object to represent the process of collecting and sharing ideas. Using this and pictorial support, we explained at the start of sessions that contributions would be shared with others interested in improving AAC.

\section{Participants}

There are no 'representative' or 'average' profiles for children with severe disabilities. We thus decided to recognise the different profiles of children who use AAC. Applying a critical case sampling strategy, we recruited information-rich participants [32] who would offer insights through their varied profiles. The sampling criteria were primary age students identified as having severe speech and physical impairments and using some form of AAC. As the first author held detailed knowledge about the students, they met with the school leadership team to select whom to invite. Five children aged 6-9 years were recruited. To avoid emphasising children's deficits, we do not consider their clinical profiles. Instead, we present descriptive accounts of their communication styles and assistive equipment used to provide additional context for our findings (Table 1). These accounts were created based on the knowledge the first author held about participants and supplemented through discussions with their class teachers. In addition to the researcher (who was present for all recordings), class-based teaching staff also took part in the research. Staff knew about individual children's communication styles and had been trained to use AAC techniques and strategies for supporting communication.

\section{Data Collection Method}

Previous research involving children with SSPIs has tended to include proxies in place of primarily engaging children in the research [2]. Given that we wanted to develop a childcentred account of communication, we considered participatory research methods as a possible methodological avenue. However, we recognised the challenges involved in managing adult driven agendas in these forms of engagement [12], particularly with children who have little or no functional speech. Thus, the observation method was chosen to record the multimodal, moment-to-moment ways in which children broadly communicated with their peers and adults in everyday contexts. The first author collected these observations through videos.

Video recording was generally arranged to minimise disruption to the class activity, positioning a small digital video camera at the edge of the classroom. Whilst we had intended to use two cameras to capture children's faces and their AAC screens, we were unable to do so as in practice as the participants became very aware and uncertain when this was trialled. We therefore chose to focus on the broadest possible view of children's whole bodies and the people around them. In total, 20 video recordings were made. One participant ('Clara') strongly disagreed with us videoing during the session and whilst she wanted to be part of the study, did not want to be recorded. In this case, detailed retrospective notes of the session were taken and the video camera was switched off in her presence. As a result, Clara's data is drawn on descriptively within our findings, rather than visually.

\section{Analytic Approach}

Video analysis was used to investigate class-based communication. As participants had little or no verbal speech, video analysis enabled us to identify and interpret interactional phenomena associated with a range of modes

\begin{tabular}{|c|c|c|c|}
\hline Name & Age & Gender & Description of communication and other assistive equipment used \\
\hline Noah & 6 & $\mathrm{M}$ & $\begin{array}{l}\text { Uses 5-10 intelligible words and a symbol communication system on a touch screen tablet, accessed } \\
\text { through hand swiping and support to finger point. Uses partner assisted manual w/c with head support. }\end{array}$ \\
\hline Maya & 7 & $\mathrm{~F}$ & $\begin{array}{l}\text { No intelligible oral speech, eye points to show interest and looks away to indicate negation, e.g. 'I don't like } \\
\text { it'/'no'. Uses symbol communication system on an eye gaze device, mounted to her w/c. Uses partner } \\
\text { assisted manual w/c with full head, torso, trunk and foot support. Partly enterally fed via g-tube and j-tube. } \\
\text { Sometimes uses neck brace and oxygen to support her breathing. Has uncontrollable repetitive movements }\end{array}$ \\
\hline Clara & 7 & $\mathrm{~F}$ & $\begin{array}{l}\text { Uses 5-10 intelligible words and can join } 2 \text { signs or gestures but signing is unclear owing to coordination } \\
\text { difficulties. Becomes very anxious with unexpected events and opts out by self-harming and moving away. } \\
\text { Uses symbol communication system on a touch screen tablet with a key guard. Walks unaided but } \\
\text { unsteadily. Sometimes uses a walking frame outdoors and helmet. }\end{array}$ \\
\hline Oscar & 8 & M & $\begin{array}{l}\text { Uses 3-5 intelligible words and some hand gesturing/signing with right hand. Uses a symbol } \\
\text { communication system on a touch screen tablet. Walks a few steps unaided and uses a walking frame and } \\
\text { helmet, weaker on his right side. }\end{array}$ \\
\hline Grace & 9 & $\mathrm{~F}$ & $\begin{array}{l}\text { Eye pointing, facial expression and tone of voice are most clear. Symbol communication system on an eye } \\
\text { gaze device that is mounted to her w/c. Uses partner assisted manual w/c with head, torso, trunk and foot } \\
\text { support. Likes to use her arms and fist to point to things and also has strong, uncontrollable movements. }\end{array}$ \\
\hline
\end{tabular}


including looking behaviours, gesture, proximity, tone of voice, as well as in-person processes including joint attention and common ground [19]. We took a whole-topart inductive approach to video analysis $[9,10]$ whereby videos were viewed multiple times and indexed to identify shorter segments involving the use of AAC technology. Of the total 20 video recordings, 11 events were identified and included in our analysis. The small volume of AAC mediated events reflects how little these were used by children. This will be discussed further within the findings.

Videos were first broadly transcribed and time-marked using InqScribe transcription software [43] in order to capture sequences of utterances of talk, gesture and movement. This enabled us to investigate question (i.) and (ii.). In order to investigate the child-led ways that communication was constructed (question iii.) we also took a social semiotic approach that centred on investigating how children used the modes available to them, for example eye pointing or gesture, in order to make meaning [3,21]. Using conversation analysis transcription conventions $[13,17]$ (see Fig. 2) we were able to capture the full repertoire of children's communicative behaviours.

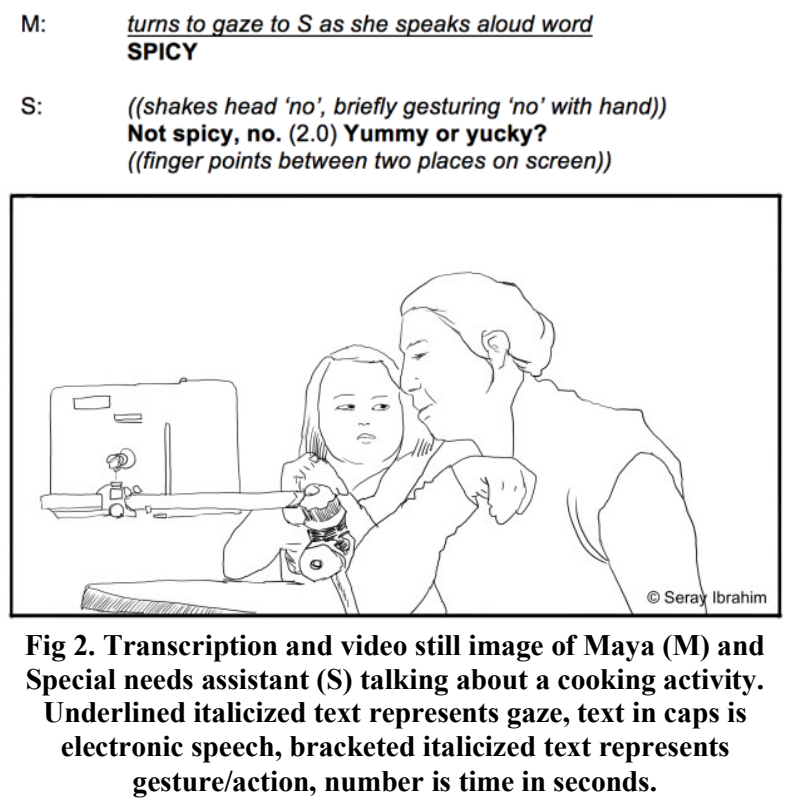

Alongside the video segments and transcriptions, we extracted stills from the videos. Still images (converted into line drawing to protect privacy) emphasised the consideration of important spatial elements and environmental factors from the videos, whereas transcription enabled us to describe utterances of talk, movement and the uptake of other modes. Fig. 2 illustrates the different contributions of each data for same event.

Using this data, we performed an inductive thematic analysis within a constructivist view that credited socially produced meaning, as described by Braun \& Clarke [7]. In doing so, we identified and coded patterns in the data set, illustrating salient dimensions that would be organised into themes. In order to apply a systematic and rigorous analysis, videos were watched multiple times so we could exhaust the different possible interpretations of events. Group viewings involving all authors enabling us to determine whether different researchers noticed similar phenomena or alternatives, testing out the different explanations of our data as we began to build on the themes. This process generated 13 coding categories that were then organized into three themes:

- Competence and agency in adult-child interactions describes how adults made assumptions about children's capabilities to communicate via AAC, consequently impacting on child agency.

- AAC as a material object describes the shift from the child's communication via technology to the AAC acting as an external object that obscured or fostered meaning.

- Misalignments and breakdowns capture how AAC and their design faculties lead to child-to-child and child-to-adult breakdowns in communication.

\section{FINDINGS}

Competence and Agency in Child-Adult Interactions

The majority of technology-mediated interactions between adults and children consisted of adults initiating communication then scaffolding the child's language by using the option of technology. During these interactions, the adult had control over the conversation and provided a structured way of addressing competence by teaching children how to use their devices operationally and also by modelling language use in specific ways. This practice inadvertently limited children's agency in employing alternative ways of expression with $\mathrm{AAC}$, e.g. to respond in more open and detailed ways, or to initiate communication for themselves. For example, in the excerpt in Fig. 3, Maya and a special needs assistant (SNA) talked about tasting an omelette they had just made. After introducing the conversation context, the SNA directed Maya to the 'descriptions' page on her device prior to asking her 'Was it yummy or yucky?'. Here, the adult taught Maya one very specific way of responding to a closed question. Maya chose to provide alternative answers that could re-direct the conversation to different qualities of the food and prompt the SNA to adopt an open ended line of questioning. Yet, the SNA rejected the relevance of Maya's responses and reoriented her to the original options, implicitly expressing her perception of Maya's limited communicative competence in that context. 
In a similar example (Fig. 4) illustrating how adults can limit children's communication agency, the researcher asked Maya a series of closed questions concerning her consent for being video recorded in the research. Instead of letting Maya choose her own vocabulary, she prompted her to the 'feelings' opinions page on her AAC device.

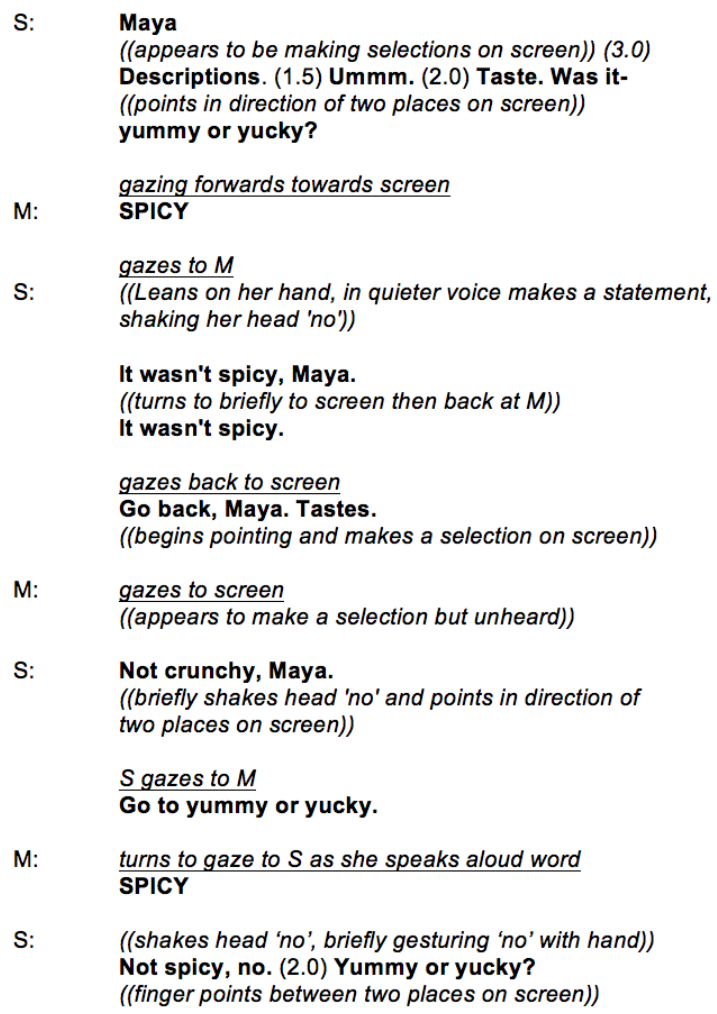

Fig. 3. Transcription of interaction between Maya (M) and Special needs assistant (S). Text in CAPS is electronic speech, underlined italicized text represents gaze, italicized text in brackets is gesture/action. Numbers in brackets are time in seconds.

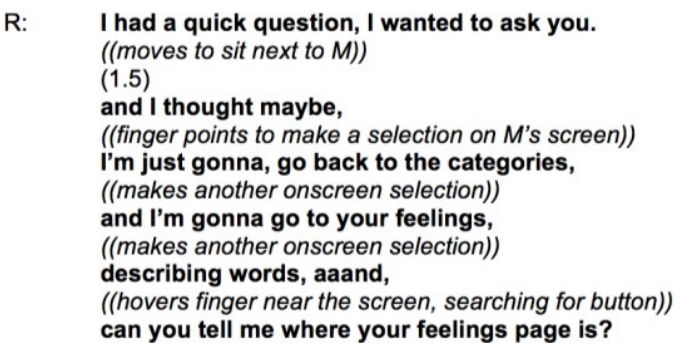

Fig. 4. Transcription of researcher's $(R)$ utterance to Maya. Italicized text in text in brackets represents gesture/action, numbers in brackets represents time in seconds.

On rarer occasions, such as the one illustrated in Fig. 5, children explicitly challenged adult assumptions of their competence to use AAC devices. During this interaction involving Maya and two adults, the teacher told the researcher that there was a problem with how Maya made onscreen selections using her eyes with her eye-control AAC device. The teacher suggested that Maya was only

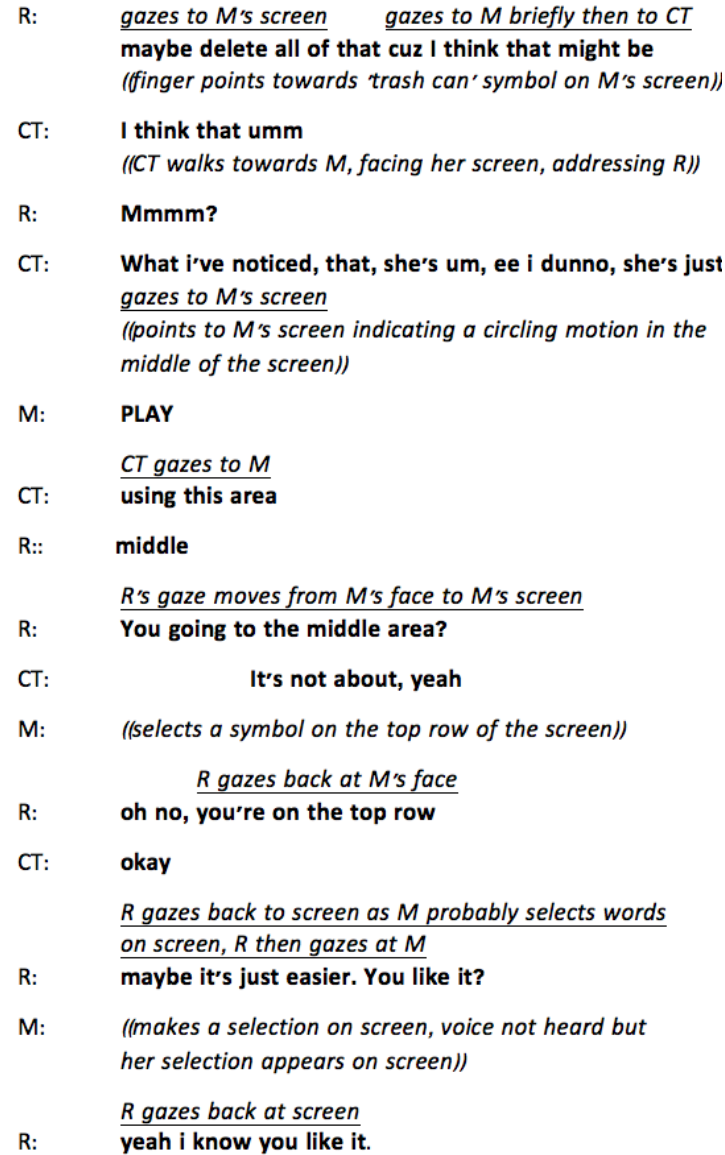

Fig. 5. Transcription of interaction between Maya (M), the class teacher $(C T)$ and researcher $(\mathrm{R})$. Text in CAPS is electronic speech, underlined italicized text represents gaze, italicized text in brackets is gesture/action.

looking towards symbols in the middle area of her screen evidencing her limited operational competence in using the device. Yet, as the researcher moved closer to observe this, Maya began to move the cursor to different locations, selecting key words and phrases, e.g. play, that changed the topic of her previous discussion with the class teacher. Through her actions, Maya exercised agency and was able to show that the assumed operational issue concerning onscreen selections was not linked with her capability to eye point.

Despite showing communicative agency through their use of technology, children more commonly chose to use other modes of communication to interact. Other participants, Grace, Clara, Oscar and Noah for example, regularly turned to their communication books instead of AAC technologies when responding to adult questions, despite AAC technologies often being more readily available to them. In support of this, throughout the 20 video recordings made over the course of 14 weeks, the five participants who all had access to AAC technologies used these infrequently in conversation. Only two of the five participants are predominantly the focus of our examples illustrating that in naturally occurring communication the participants used 
other modes to communicate in ways that were more appropriate to them in the moment. By rejecting technology in this way, children ascertained agency over how they communicated in ways of their own choosing.

\section{AAC as a Material Object}

AAC technologies provide people who do not have natural speech with a new mode of expression. Paradoxically, in the majority of videos analysed, the AAC technology itself was often explicitly talked about. Instead of mediating communication it became a visible object that was attended to. One reason for this was related to apparent technical faults with the device. In Fig. 6, the researcher moved next to Maya's AAC screen, commenting that Maya navigated to a blank page. The initial topic of discussion was disrupted as the researcher began to talk about the device having inadequate language content. Attending only to the screen, the researcher missed Maya's subtle communicative modes e.g. looking behaviours and facial expression that may have offered information concerning her affect or intentions.

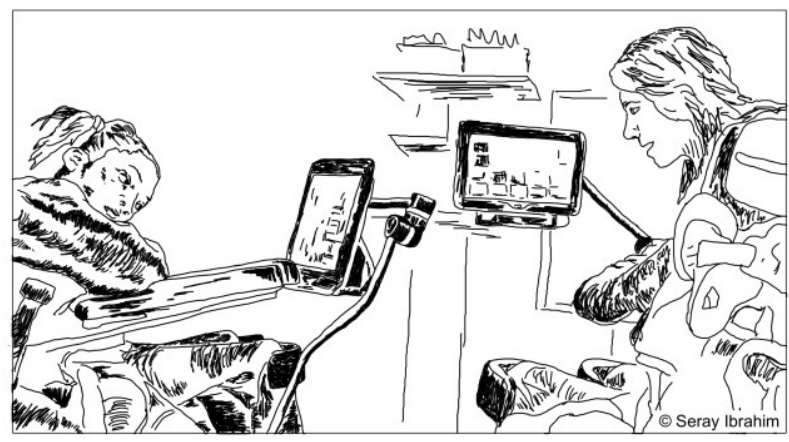

Fig 6. Video still image of Maya (right) \& researcher interacting whilst Grace (left) is distanced from the conversation.

The focus of AAC as an object also resulted from the ordering of AAC and people, which placed the focus of the interaction overwhelmingly on the device. In a separate occurrence within the same video presented in Fig. 6, Grace and Maya were orientated towards each other at an angle but partially hidden behind their screens. This was mainly due to Grace's eye gaze access requirement which was to position the device in front of her at eye level. However, the structural arrangement of both girls and technology credited value to technology. For Grace who was positioned on the left, this blocked her from being directly involved in

C: ((walks towards $G$ and $M$ and stands on $G$ 's right side, facing M's SGD screen))

G's gaze shifts from screen to $C$ Are you on your way?

((unclear speech, CT begins pointing towards the heart-shaped cards that she and $M$ have been working on then points to M's AAC screen as she speaks))

M: $\quad$ gazes towards $C T$ and $C$ for 2.5 seconds then back to screen

C: $\quad$ gazes to the cards the CT is holding then to M's screen ((walks back towards home corner))

Fig. 7. Transcription of interaction between Clara (C), teacher (CT) and Maya (M). Text in brackets is gesture/action, underlined italicized text represents gaze. interaction and forced her to adopt a passive role. As time passed, Grace stretched upwards to attempt to look at Maya and her screen but owing to the chlidren's positioning and technology barriers, she was unable to do so. Given these structural arrangements children were not able to 'create' context through accessing what the other was doing.

While the examples so far emphasise how the design of AAC technology carved its role and presence as an object, this was also socially shaped. Specifically, AAC devices were used by adults as archival objects that were re-shared with others without the child's consent despite his/her presence. In three occasions in our data, an adult recounted a child's prior communicative act by accessing and reading out a previously constructed utterance with the device. This is illustrated in Fig. 7 where the class teacher and Maya have finished talking about activities that Maya liked. As Clara, another participant of the study, wandered towards them, the teacher seized this opportunity to repeat to Clara what Maya had just said via her technology.

The potential infringement of child agency in the adult sharing archived speech was brought to the foreground in Fig. 8. presented below. When asked by the adult, Grace refused to feed back to the group about her weekend by rejecting the AAC, turning away and raising her arm between herself and the adult. Despite her assertion not to communicate in this context, the adult used her earlier AAC speech to recount Grace's weekend to the group, apparently violating her stated desire not to share.

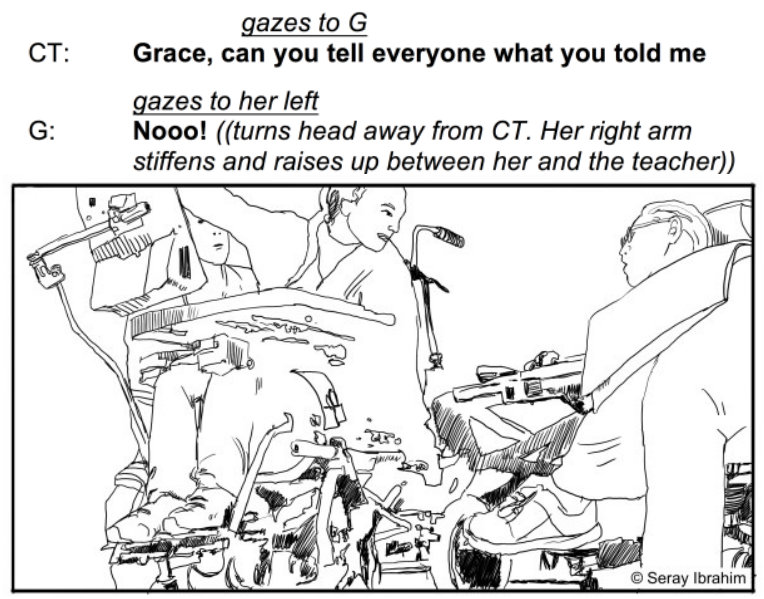

Fig 8. Transcription and video still image of class group session involving Grace, teacher and other children.

Underlined text represents gaze, italicized text in brackets represents gesture/action.

\section{Misalignments and Breakdowns}

Earlier we considered the prevalence of adult conversation starters and subsequent child language scaffolding. There were times, however, when children used their AAC to initiate themselves, e.g. through phrases and sentence starters, engaging in 'emergent' (not adult-planned) communication with others. During these occasions, adultchild interactions in particular were characterised by 
difficulties, both in how the adult interpreted the child's utterance and the child's ability to engage in selfclarification. For example, Maya had been sitting opposite Grace and the researcher but was not involved in their conversation (Fig. 9). Suddenly Maya used her AAC device to say 'I'm sorry'. The researcher interpreted this first to mean Maya was apologising, asking 'what are you sorry about Maya?' and then as a request to join in asking 'do you want to join in?'. Maya next generates 'please' on her device and the researcher treats 'please' as a confirmation that Maya wants to join in saying 'please, ok alright'. However, Maya then says 'I'm sorry' again but this is not attended to by the researcher. The intended meaing of Maya's second 'I'm sorry' remains unknown. It suggests the researcher is progressing on the basis of an unsubstantiated hypothesis that Maya wants to join in.

\begin{tabular}{|c|c|}
\hline R: & $\begin{array}{l}\text { ((facing G)) } \\
\text { so let's say- }\end{array}$ \\
\hline M: & I'M SORRY \\
\hline R: & $\begin{array}{l}\text { gazes to } M \\
\text { what you sorry about, Maya? } \\
\text { ((turns body toward } M \text {, smiling)) }\end{array}$ \\
\hline G: & $\frac{\text { gazes to } M}{((\text { smiling }))}$ \\
\hline R: & did you want to join in? \\
\hline M: & PLEASE \\
\hline R: & Please. ((smiling)). Ok, alright. \\
\hline M: & $1-$ \\
\hline R: & $\begin{array}{l}\text { Yeah? ((turns to } G \text { briefly whilst pointing to } M) \text { ) } \\
\text { Your buddy's saying something } \\
\text { Yeah ((turns to } M \text { again)) }\end{array}$ \\
\hline G: & $\begin{array}{l}\text { ((smiling and reaching upwards to look over her own } \\
\text { device to } M \text {, a crack is heard as G's movement dislodges } \\
\text { her wheelchair tray)) }\end{array}$ \\
\hline M: & I'M SORRY \\
\hline R: & $\begin{array}{l}\text { ((diverts attention to attend to G's tray)) } \\
\text { Uh huh? } \\
\text { ((turns to speak to G)) } \\
\text { Oh your tray's falling down, my lovely. }\end{array}$ \\
\hline
\end{tabular}

Fig. 9. Transcription of interaction with researcher (R), Grace (G) and Maya (M). Text caps is electronic speech, text in brackets is gesture/action, underlined italicized is gaze.

By contrast as Fig. 3 earlier illustrated, adult reactions to misalignments were different. Sometimes adults only credited legitimate and intelligible child responses, whereas in other cases, adults made assumptions about what the child might be intending. In both cases, adults treated the child's response as ambiguous whereas in Fig.9, the adult expanded on what they saw as an ambiguous response (I'm sorry) adding interpretations for what the chid may have intended to say. In Fig.9, Maya stops adding more detail about what she is saying when the researcher becomes distracted and the topic changes.

Misalignments also occurred during AAC-initiated child talk between pairs of mixed ability children. AAC technologies that belonged to children were largely personalised to their individual characteristics through their access methods, representation of language and vocabulary content. Thus, each child had a separate language set up creating a rigid structure for flexibly managing to and fro communication within the temporal requirements of a conversation. In Fig. 10, Maya who was in the presence of Grace initiated the word "play" using her AAC device. Grace did not have access to play-related language on her device at the time, and Maya did not have the words to respond to Grace's excited reaction to her initial comment to 'play'. Consequently, AAC was abandoned fully by Grace, who chose instead to use looking behaviours, orientation and vocalisation, and partly by Maya, who used her device for key words but also eye points to express her interest in playing with Grace. In summary, both girls' technologies alone were insufficient for building on Maya's utterance when the moment called for it.

\begin{tabular}{|c|c|}
\hline M: & PLAY \\
\hline R: & $\frac{\text { gazes to } M}{\text { you wanna play? }}$ \\
\hline M: & PLAY \\
\hline G: & gazes to $M$ briefly then to $R$ \\
\hline R: & $\begin{array}{l}\text { gazes at } G \\
\text { shall we? }\end{array}$ \\
\hline G: & ((raising her head from her chest,smiling)) \\
\hline M: & gazes to $G$ \\
\hline R: & gazes to $M$ \\
\hline G: & yeah \\
\hline R: & with Grace? \\
\hline M: & $\begin{array}{l}((M \text { turns her head back towards midline, } \\
\text { possibly towards } R))\end{array}$ \\
\hline $\mathrm{R}:$ & $\begin{array}{l}\text { gazes at } G \\
\text { shall we? }\end{array}$ \\
\hline G: & $\begin{array}{l}\text { gaze drops slightly, possibly towards } A A C \text { screen } \\
\text { then gazes back at } R \\
\text { yah }\end{array}$ \\
\hline R: & what now now? \\
\hline G: & $\begin{array}{l}\text { ((nods head and smiles)) } \\
\text { yah }\end{array}$ \\
\hline
\end{tabular}

Fig. 10. Transcription of interaction between Maya (M), researcher $(R)$ and Grace $(G)$. Text in brackets is gesture/action, underlined italicized text represents gaze.

\section{DISCUSSION}

The goal of this empirical study was to 'talk back' to interaction designers by elucidating the everyday technology experiences of children with SSPI. A secondary goal was to reframe the way interaction design has sometimes understood communication through technology, i.e. through a transmission model, by introducing a situated, multimodal view of communication present in theoretical and empirical research in the AAC field. The discussion presents a critical analysis of our findings and identifies new design opportunities for AAC technology and beyond.

\section{Communication is embodied}

The children of our study used technology much less frequently than their other modes of communication. This was despite all five children having access to their technologies, and being encouraged to use them by their 
teachers. Communicating through other modes provided a faster and more efficient way of expression than AAC. It also enabled them to ascertain control over self-initiated communication and their responses to others, given that the former was otherwise heavily controlled by adults during AAC use. In using modes other than technology, children expressed themselves persuasively through embodied means. For example, resisting to share what she did at the weekend, Grace tensed her body and pushed herself upwards in her chair, turning away and lifting her arm to create a barrier from the adult asking her a question. Other times, however, these communicative signs were expressed more subtly, and in turn missed by communication partners.

This reinforces one of the most robust findings in AAC research, i.e. that children rely on multiple modes to communicate and these choices are closely related to context, partners, task and intent [1]. It also shows the prevalence of embodied communication over spoken language use, highlighting an important gap in technology design for children with SSPI, which has been primarily driven by a cognitive approach to language and literacy skills. Therefore, an opportunity exists for further design research that seeks to design for the embodied experiences that motivate children with SSPIs to communicate with others. For example, following the observation that children's embodied expressions can be subtle and go unnoticed, technology could record and draw attention to these expressions during interactions, making the role of alternative modes visible and central to communication.

\section{Respecting child competence and agency}

According to Light, communicative competence is achieved through four inter-related domains of linguistic, operational, social and strategic competence [22,29]. For AAC users, linguistic competence is concerned with understanding the native language of a community and mastering the 'linguistic code' required by the AAC system. Operational competence is having the technical skills to proficiently use a system. Social competence is having knowledge, skill and judgement in the social rules of communication, e.g. discourse strategies and different communicative functions. Lastly, strategic competence refers to how AAC users drawing on compensatory strategies for communicating effectively within restrictions.

The three adults of this study primarily focused on children's operational and linguistic competence, showing their low expectations of children's competence by highly scaffolding their questions and children's replies. Children's lack of self-management during emergent communication could be interpreted as evidence that this scaffolding was required. These findings together indicate the high entry level requirements for accessing $\mathrm{AAC}$, and as a consequence the requirement to use $\mathrm{AAC}$ as an instructional tool long before children can exercise agency in their communication using this technology. Even though adult scaffolding may have been beneficial for some of the children, it was also applied in a rigid rather than a dynamic way that was particularly problematic with one participant, Maya whose competence seemed to go unnoticed. Maya demonstrated operational competence in using her device to orchestrate a new topic by looking at different places, and in a different occasion she evidenced strategic competence when expressing her own opinions about a cooking activity. Drawing on the well established principle of gradually and dynamically scaffolding learning [42], our study underscores the importance for AAC technologies to develop and 'grow' in pace with a child's competence while placing child agency in communication at the forefront of design. It also recognises that children might have an uneven profile of competences that relate to their social, strategic, operational and linguistic skills suggesting the need for nuanced approach to how AAC is personalized.

Children's agency was not only constrained by the high entry barriers to using AAC, but also by how little control they had in regulating who had access to their disclosure and how it was interpreted. Adults approached a child's AAC as an archival object that could be used to retell a child's utterances to others. This practice brought to question children's agency in the moment of retelling, and their role in consenting to share their disclosure beyond its original context. This demonstrates the importance of problematizing privacy management in the context of AAC [35]. Our findings suggest the importance of creating new, nuanced ways of regulating the temporal and spatial dimension of disclosure through AAC devices - for example by allowing a child to control the ephemerality of their utterances or the spatial arrangement of their display to signal their desire not to disclose beyond the original context in which an utterance occurred.

\section{Regulating the status of AAC in communication}

Disability can be socially produced through the ordering of the social and material [30]. This perspective was prevalent within our findings: AAC created physical barriers between children and communication partners, stopping them from seeing what others were doing and limiting their involvement in conversations. In another instance, technical or operational problems re-directed the adult's attention from the child to AAC. By gaining prominence and thus value through its form and function, technology took precedence over communication becoming the central object of attention. This echoes previous AAC literature claiming that the function and form of these systems should be critically considered within the complex and dynamic communication environments in which they are used [37].

The obstruction created by the physical and technical presence of $\mathrm{AAC}$, alongside the earlier insight that $\mathrm{AAC}$ is not always the right mode in the moment, prompts us to consider the importance of dynamically regulating its status within interaction through its form or spatial arrangement. Previous research has explored how hardware devices can shift in shape and in function to support a diversified set of 
interactions. Recognising the technology-driven nature of this work, these researchers have begun to consider the kind of scenarios that may benefit from these innovations [40]. We posit that shape-shifting AAC may provide a child with options to mould the status of technology during communication. Alternatively, AAC may be designed to offer flexibility and child control in its spatial arrangement, for example through new ways of mounting the device for the child to fluidly move it in and out of focus.

\section{Supporting child-initiated communication}

Our study showed that the communicative functions for which AAC devices were used were largely limited in use, with many instances of adults teaching children how to respond to specific questions with specific response options. This meant children had few opportunities to learn how to participate in more diverse communication situations with adults and other children with SSPI, perpetuating unbalanced conversation dynamics that are typically structured by naturally speaking conversation partners $[9,10]$. Alongside its role in confirming past findings, our study exposed a number of misalignments occurring during child-initiated communication informing new design scenarios for future improvements of $\mathrm{AAC}$, or new technology design.

\section{Establishing common ground in AAC communication}

Much of the AAC research focuses on communication between children with SSPI and competent communication partners. Even though children with SSPI typically attend special schools and socialise with children of similar profiles, it is unclear if AAC can support their communication. Our research provides some evidence to show how AAC design may inhibit these opportunities. One of the participants initiated a playful interaction with her peer using AAC. But given that children's screens and language content were different at this critical moment, these children were unable to build on the initial AAC utterance. This finding reaffirms the need to look beyond the sender-receiver model for AAC and highlights the importance of supporting the establishment of common ground. In practical terms technology could detect and share language pages between AAC users, allowing them to synchronise their content, and thus gaining access to high frequency vocabulary relating to the topic of discussion.

\section{Self-clarifying communication misalignments}

Conversations involving naturally speaking partners can result in misalignments due to ambiguities in how utterances are constructed, or interpreted. However, given their available resources, naturally speaking partners build on prior turns in different ways to engage in forms of repair [36], for example, through word replacement. When children with SSPI initiated their own topics with AAC utterances, adults often misinterpreted the meaning of these, either through unsubstantiated guesses over what the child meant or by treating these utterances as illegitimate given the conversational context. In contrast to the ability of naturally speaking partners to self-clarify [36], in those situations children with SSPI did not have the resources through expressive modes to signal that problems had occurred in understanding, or to repair such issues. AAC could offer a child with lightweight ways to explicitly signal that a problem in understanding is occurring, toward developing new skills for negotiating these instances.

\section{CONCLUSION}

This paper reported a qualitative 14-week field study at a special school. Our research aim was to examine how communication manifests in five children with SSPI who use AAC in school, and the mediating role of AAC design. Videos of communication incidents involving children and technology were collected. Inductive video analysis was then carried out applying a multimodal and social semiotic approach. Our analysis approached communication from three lenses: children's choice of modes (a child view), their interactions with each other and technology (an interactional view), and the ordering of people and technology (a structural view). This enabled us to identify the kinds of communication achieved through and around $\mathrm{AAC}$ and to unpack how the design of AAC impacts on this communication. Our paper contributes to the field of interaction design and AAC research with four design opportunities: incorporating an embodied view of communication; designing to emphasise children's competence and agency, regulating the presence, prominence and value of AAC, and; supporting children in maintaining self-initiated communication.

One methodological limitations we faced was the limited capture of repeated incidents of AAC-mediated communication in naturally occurring interactions. Additional research is needed from more diverse contexts to enrich our findings, in line with what Stebbins calls concatenation i.e. incremental development of theory [39]. This could include considering the role of conversation partners and the impact of varied language displays on communication. Our study should not be interpreted as providing clear solutions to this complex problem space, but rather identifying new avenues for a future design agenda that brings interaction designers closer to the concerns of young children with SSPI who use technology. In particular, we hope that future design work will move beyond the transmission of information framing of technology to design for situated, embodied and coconstructed communication.

\section{ACKNOWLEDGEMENTS}

This research was funded by an ESRC doctoral studentship. Conference participation was made possible through a SIGCHI Student Travel Grant award. We wish to thank Dr Bezemer, Prof Kress, Dr Korkiakangas and Prof Jewitt for their supportive guidance at various stages of this work. We are also grateful to our anonymous reviewers for their feedback and to Alain Urrutia for his guidance on line drawing. Lastly, we are indebted to the children, families and school staff who donated their time so generously. 


\section{REFERENCES}

1. Susan Baxter, Pam Enderby, Philippa Evans, and Simon Judge. 2012. Barriers and facilitators to the use of high-technology augmentative and alternative communication devices: a systematic review and qualitative synthesis: AAC barriers and facilitators review. International Journal of Language \& Communication Disorders 47, 2: 115-129. https://doi.org/10.1111/j.1460-6984.2011.00090.x

2. Laura Benton and Hilary Johnson. 2015. Widening participation in technology design: A review of the involvement of children with special educational needs and disabilities. International Journal of ChildComputer Interaction 3-4: 23-40. https://doi.org/10.1016/j.ijcci.2015.07.001

3. Josephus Johannes Bezemer and Gunther R. Kress. 2016. Multimodality, learning and communication: a social semiotic frame. Routledge, Taylor \& Francis Group, London ; New York.

4. Rolf Black, Annalu Waller, Ross Turner, and Ehud Reiter. 2012. Supporting Personal Narrative for Children with Complex Communication Needs. $A C M$ Transactions on Computer-Human Interaction 19, 2: 1-35. https://doi.org/10.1145/2240156.2240163

5. Steven Bloch and Ray Wilkinson. 2004. The Understandability of AAC: A Conversation Analysis Study of Acquired Dysarthria. Augmentative and Alternative Communication 20, 4: 272-282. https://doi.org/10.1080/07434610400005614

6. Peter Börjesson, Wolmet Barendregt, Eva Eriksson, and Olof Torgersson. 2015. Designing technology for and with developmentally diverse children: a systematic literature review. In Proceedings of the 14th International Conference on Interaction Design and Children, 79-88. https://doi.org/10.1145/2771839.2771848

7. Virginia Braun and Victoria Clarke. 2006. Using thematic analysis in psychology. Qualitative Research in Psychology 3, 2: 77-101. https://doi.org/10.1191/1478088706qp063oa

8. Rhian Davies, Skip Marcella, Joanna McGrenere, and Barbara Purves. 2003. The ethnographically informed participatory design of a PD application to support communication. ACM SIGACCESS Accessibility and Computing, 77-78: 153. https://doi.org/10.1145/1029014.1028658

9. Sharon J. Derry, Roy D. Pea, Brigid Barron, Randi A. Engle, Frederick Erickson, Ricki Goldman, Rogers Hall, Timothy Koschmann, Jay L. Lemke, Miriam Gamoran Sherin, and Bruce L. Sherin. 2010. Conducting Video Research in the Learning Sciences: Guidance on Selection, Analysis, Technology, and Ethics. Journal of the Learning $\begin{array}{cccc}\text { Sciences } & 19, & 1: & 3-53 .\end{array}$ https://doi.org/10.1080/10508400903452884

10. Frederick Erickson. Definition and Analysis of Data from Videotape: Some Research Procedures and Their Rationales. In Handbook of Complementary Methods in Education Research.

11. Luciana C.L. de Faria Borges, L.V.L. Filgueiras, Cristiano Maciel, and Vinicius C. Pereira. 2012. Customizing a Communication Device for a Child with Cerebral Palsy Using Participatory Design Practices: Contributions Towards the PD4CAT Method. In Proceedings of 11th Brazilian Symposium on Human Factors in Computing Systems, 57-66. http://dl.acm.org/citation.cfm?id=2393536.2393544

12. L.-A. Gallacher and M. Gallagher. 2008. Methodological Immaturity in Childhood Research?: Thinking through 'participatory methods'. Childhood 15, 4: 499-516. https://doi.org/10.1177/0907568208091672

13. Charles Goodwin. 1981. Conversational organization: interaction between speakers and hearers. Academic Press, New York.

14. D. Jeffery Higginbotham. 2009. In-Person Interaction in AAC: New Perspectives on Utterances, Multimodality, Timing, and Device Design. Perspectives on Augmentative and Alternative Communication $\quad 18, \quad 4: \quad 154$. https://doi.org/10.1044/aac18.4.154

15. Anthony J. Hornof. 2009. Designing with children with severe motor impairments. In Proceedings of the SIGCHI Conference on Human Factors in Computing Systems, 2177. https://doi.org/10.1145/1518701.1519032

16. Anthony Hornof, Haley Whitman, Marah Sutherland, Samuel Gerendasy, and Joanna McGrenere. 2017. Designing for the "Universe of One": Personalized Interactive Media Systems for People with the Severe Cognitive Impairment Associated with Rett Syndrome. In Proceedings of the 2017 CHI Conference on Human Factors in Computing Systems, 2137-2148. https://doi.org/10.1145/3025453.3025904

17. Gail Jefferson. 2004. Glossary of transcript symbols with an introduction. In Conversation Analysis: Studies from the First Generation. John Benjamins., Amsterdam, pp: 13-31.

18. Jeanne M. Johnson, Ella Inglebret, Carla Jones, and Jayanti Ray. 2006. Perspectives of speech language pathologists regarding success versus abandonment of AAC. Augmentative and Alternative Communication 22, 2: 85-99. https://doi.org/10.1080/07434610500483588 
19. Barbara B. Kawulich. 2005. Participant Observation as a Data Collection Method. Forum Qualitative Sozialforschung / Forum: Qualitative Social Research 6, 2. Retrieved August 22, 2017 from http://www.qualitative-

research.net/index.php/fqs/article/view/466

20. Arlene W. Kraat. 1987. Communication Interaction between Aided and Natural Speakers: A State of the Art Report. Second Edition. Trace Center, University of Wisconsin-Madison, Waisman Center, 1500 Highland Ave. Retrieved August 11, 2017 from https://eric.ed.gov/?id=ED297504

21. Gunther R. Kress. 2010. Multimodality: a social semiotic approach to contemporary communication. Routledge, London; New York.

22. Janice Light. 1989. Toward a definition of communicative competence for individuals using augmentative and alternative communication systems. Augmentative and Alternative Communication 5, 2: 137-144. https://doi.org/10.1080/07434618912331275126

23. Janice Light. 1997. "Let's go star fishing": reflections on the contexts of language learning for children who use aided AAC. Augmentative and Alternative Communication 13, 3: 158-171. https://doi.org/10.1080/07434619712331277978

24. Janice Light. 1997. "Communication is the essence of human life": reflections on communicative competence. Augmentative and Alternative Communication 13, 2: 61-70. https://doi.org/10.1080/07434619712331277848

25. Janice Light, Barbara Collier, and Penny Parnes. 1985. Communicative interaction between young nonspeaking physically disabled children and their primary caregivers: Part I-discourse patterns. Augmentative and Alternative Communication 1, 2: 74-83.

https://doi.org/10.1080/07434618512331273561

26. Janice Light and Kathryn Drager. 2004. Re-thinking Access to AAC Technologies for Young Children: Simplifying the Learning Demands. Perspectives on Augmentative and Alternative Communication 13, 1: 5. https://doi.org/10.1044/aac13.1.5

27. Janice Light and Kathryn Drager. 2007. AAC technologies for young children with complex communication needs: State of the science and future research directions. Augmentative and Alternative Communication 23, 3: 204-216. https://doi.org/10.1080/07434610701553635

28. Janice Light and David McNaughton. 2013. Putting People First: Re-Thinking the Role of Technology in Augmentative and Alternative Communication
Intervention. Augmentative and Alternative Communication 29, 4: 299-309. https://doi.org/10.3109/07434618.2013.848935

29. Janice Light and David McNaughton. 2014. Communicative Competence for Individuals who require Augmentative and Alternative Communication: A New Definition for a New Era of Communication? Augmentative and Alternative Communication 30, 1: 1-18 https://doi.org/10.3109/07434618.2014.885080

30. Ingunn Moser. 2006. Disability and the promises of technology: Technology, subjectivity and embodiment within an order of the normal. Information, Communication \& Society 9, 3: 373395. https://doi.org/10.1080/13691180600751348

31. Joan Murphy, Ivana Marková, Sarah Collins, and Eleanor Moodie. 1996. AAC systems*: obstacles to effective use. International Journal of Language \& Communication Disorders 31, 1: 31-44. https://doi.org/10.3109/13682829609033150

32. Michael Quinn Patton. 1990. Qualitative evaluation and research methods. Sage Publications, Newbury Park, Calif.

33. Graham Pullin. 2009. Design meets disability. MIT Press, Cambridge, Mass.

34. Graham Pullin and Shannon Hennig. 2015. 17 Ways to Say Yes: Toward Nuanced Tone of Voice in AAC and Speech Technology. Augmentative and Alternative Communication 31, 2: 170-180. https://doi.org/10.3109/07434618.2015.1037930

35. Joseph Reddington and Lizzie Coles-Kemp. 2011. Trap Hunting: Finding Personal Data Management Issues in Next Generation AAC Devices. In Proceedings of the Second Workshop on Speech and Language Processing for Assistive Technologies, 3242. Retrieved September 18, 2017 from http://dl.acm.org/citation.cfm?id=2140499.2140505

36. Emanuel A. Schegloff, Gail Jefferson, and Harvey Sacks. 1977. The Preference for Self-Correction in the Organization of Repair in Conversation. Language 53, 2: 361-382. https://doi.org/10.2307/413107

37. Martine M. Smith. 2015. Language Development of Individuals Who Require Aided Communication: Reflections on State of the Science and Future Research Directions. Augmentative and Alternative Communication 31, 3: 215-233. https://doi.org/10.3109/07434618.2015.1062553

38. Kiley Sobel, Alexander Fiannaca, Jon Campbell, Harish Kulkarni, Ann Paradiso, Ed Cutrell, and Meredith Ringel Morris. 2017. Exploring the Design Space of AAC Awareness Displays. In Proceedings 
of the 2017 CHI Conference on Human Factors in Computing Systems, 2890-2903. https://doi.org/10.1145/3025453.3025610

39. Robert A. Stebbins. 2001. Exploratory research in the social sciences. Sage Publications, Thousand Oaks, Calif.

40. Miriam Sturdee, Paul Coulton, and Jason Alexander. 2017. Using Design Fiction to Inform ShapeChanging Interface Design and Use. The Design Journal 20, sup1: S4146-S4157. https://doi.org/10.1080/14606925.2017.1352913

41. G.C. Vanderheiden. A journey through early augmentative communication and computer access. PubMed - NCBI. Retrieved August 14, 2017 from https://www.ncbi.nlm.nih.gov/pubmed/17642032

42. Lev Semenovich Vygotsky. 1981. Mind in society: the development of higher psychological processes. Harvard Univ. Press, Cambridge, Mass.

43. InqScribe: Simple Software for Transcription and Subtitling. Retrieved August 25, 2017 from https://www.inqscribe.com 